\title{
Pyrenophora tritici-repentis Race 4 Isolates Cause Disease on Tetraploid Wheat
}

\author{
Jingwei Guo, ${ }^{1}$ Gongjun Shi, ${ }^{1}$ Audrey Kalil, ${ }^{2}$ Andrew Friskop, ${ }^{1}$ Elias Elias, ${ }^{3}$ Steven S. Xu, ${ }^{4}$ Justin D. Faris, ${ }^{4}$ and \\ Zhaohui Liu ${ }^{1, \dagger}$ \\ ${ }^{1}$ Department of Plant Pathology, North Dakota State University, Fargo, ND 58108 \\ 2 Williston Research Extension Center, North Dakota State University, Williston, ND 58801 \\ ${ }^{3}$ Department of Plant Sciences, North Dakota State University, Fargo, ND 58108 \\ ${ }^{4}$ USDA-ARS Cereal Crops Research Unit, Edward T. Schafer Agricultural Research Center, Fargo, ND 58102 \\ Accepted for publication 18 June 2020.
}

ABSTRACT

\begin{abstract}
The ascomycete fungus Pyrenophora tritici-repentis is the causal agent of $\tan$ spot of wheat. The disease can occur on both common wheat (Triticum aestivum) and durum wheat (T. turgidum ssp. durum) and has potential to cause significant yield and quality losses. The fungal pathogen is known to produce necrotrophic effectors (NEs) that act as important virulence factors. Based on the NE production and virulence on a set of four differentials, $P$. tritici-repentis isolates have been classified into eight races. Race 4 produces no known NEs and is avirulent on the differentials. From a fungal collection in North Dakota, we identified several isolates that were classified as race 4 . These isolates caused no or little disease on all common wheat lines including the differentials;
\end{abstract}

however, they were virulent on some durum cultivars and tetraploid wheat accessions. Using two segregating tetraploid wheat populations and quantitative trait locus mapping, we identified several genomic regions significantly associated with disease caused by two of these isolates, some of which have not been previously reported. This is the first report that race 4 is virulent on tetraploid wheat, likely utilizing unidentified NEs. Our findings further highlight the insufficiency of the current race classification system for $P$. tritici-repentis.

Keywords: genetics and resistance, host selective toxins, inverse gene-forgene model, mycology, pathogenicity test, QTL mapping
Tan spot is caused by the necrotrophic fungal pathogen Pyrenophora tritici-repentis (Died.) Drechs. (anamorph: Drechslera tritici-repentis (Died.) Shoem.). This disease was first reported in the United States in the 1940s (Barrus 1942), but it was rarely observed until the 1970s when no-tillage practices were widely adopted (Hosford 1982; reviewed in Faris et al. 2013; Rees and Platz 1992). The typical symptoms on susceptible cultivars include tan-colored necrotic lesions, which are often surrounded by chlorotic halos or extensive chlorosis. These symptoms are associated with fungal-produced necrotrophic effectors (NEs), previously known as host-selective toxins (HSTs) (reviewed in Faris et al. 2013). In the last several decades, the disease has become one of the economically important foliar diseases in all major wheat growing regions of the world (reviewed in Faris et al. 2013). The fungal infection damages leaf tissues reducing photosynthesis activity, which can result in significant yield losses. Yield losses of nearly 50\% have been reported in Australia (Rees et al. 1982). The disease can also cause red smudge on wheat kernels, particularly in durum wheat, which can lead to downgrading of wheat grains (Fernandez et al. 1996).

Outbreaks of tan spot were thought to be attributed by the adoption of conservation agriculture practices to reduce erosion and maintain soil fertility. Crop rotation, residue management, and fungicide application can be integrated to manage tan spot of wheat. However, cultural practices and fungicide applications are not

†Corresponding author: Z. Liu; zhh.liu@ndsu.edu

Funding: Financial support provided by North Dakota State Board of Agricultural Research and Education (Wheat Research), North Dakota Wheat Commission (Wheat Research), and the National Institute of Food and Agriculture (Hatch Project/ND-02234).

The author(s) declare no conflict of interest.

(C) 2020 The American Phytopathological Society always effective. For example, it has been documented that P. tritici-repentis isolates have developed resistance to commonly used fungicides (Murray and Brennan 2009). The most cost effective and environmentally friendly way is to use resistant cultivars (Faris et al. 2013; Friskop and Liu 2016).

The wheat $-P$. tritici-repentis pathosystem follows an inverse gene-for-gene model where NEs produced by the pathogen interact with the products of the host sensitivity genes to induce necrosis or chlorosis leading to disease. Therefore, these NEs act as important virulence factors. To date, three NEs have been identified from P. tritici-repentis, namely Ptr ToxA, Ptr ToxB, Ptr ToxC, and the wheat genes interacting with them are $T s n 1$, Tsc2, and Tsc1, respectively (reviewed in Ciuffetti et al. 2010; Faris et al. 2013). Ptr ToxA is a small protein $(\sim 13.2 \mathrm{kDa})$ that induces necrosis, and it is encoded by the single copy gene ToxA (Balance et al. 1996; Ciuffetti et al. 1997; Manning et al. 2013). ToxA is also produced by two other wheat fungal pathogens, Parastagonospora nodorum and Bipolaris sorokiniana, to cause disease on wheat upon recognition by the product of the Tsn1 gene (Friesen et al. 2006, 2018; Liu et al. 2006; McDonald et al. 2018; Navathe et al. 2020). It was shown that a genomic segment containing the ToxA gene was transferred from one fungal pathogen to another through horizontal gene transfer events (Friesen et al. 2006; McDonald et al. 2018). Ptr ToxB is also a small protein, and, unlike Ptr ToxA, it induces chlorosis, and has a smaller molecular size $(6.61 \mathrm{kDa})$. The fungal gene encoding Ptr ToxB, ToxB, has been cloned and was shown to be present in multiple copies (Martinez et al. 2001, 2004; Strelkov et al. 2006). The ToxB gene is also present in P. bromi, a fungus causing leaf disease on grasses (Andrie et al. 2008). Some races of $P$. triticirepentis carry a nonfunctional form of Tox $B$, designated toxb (Amaike et al. 2008; see below). Ptr ToxC is a chlorosis-inducing $\mathrm{NE}$ and was initially characterized as a nonionic, polar, low molecular weight secondary metabolite (Effertz et al. 2002). The chemical structure of Ptr ToxC and fungal gene responsible for its production remains unknown. 
The current classification system defines eight races for $P$. triticirepentis, which is largely based on their ability to produce individual or a combination of the three NEs. This correlates with their virulence on a set of four common wheat lines including Salamouni (universally resistant), Glenlea (sensitive to Ptr ToxA), 6B662 (sensitive to Ptr ToxB), and 6B365 (sensitive to Ptr ToxC) (Lamari et al. 2003). Two durum lines, Coulter (sensitive to Ptr ToxA) and 4B1149 (insensitive to all NEs), are sometimes included in the differential set (Lamari et al. 1995), but they do not increase the power to describe additional races. All virulent races produce one known NE or more and are virulent on the differential lines carrying corresponding sensitivity gene. In contrast, race 4 produces no known NE and is avirulent to all the differentials. Using this classification system, the $P$. tritici-repentis populations from different geographic locations have been characterized (Abdullah et al. 2017a; Aboukhaddour et al. 2013; Bertagnolli et al. 2019; Gamba et al. 2012; Kamel et al. 2019; Sarova et al. 2005). Races 1 and 2 were found to be predominant in North and South America, and Australia, and relatively complicated race structures were found in the Middle East, North Africa, and Caucasus regions (Kamel et al. 2019). In addition, there were isolates identified in several studies that do not conform to the current race classification system (Ali and Francl 2002; Ali et al. 2010; Benslimane 2018; Kamel et al. 2019).

Race 4 was first described as pathotype 4 (nec- chl-), which did not produce any necrosis and chlorosis symptom on wheat differentials (Lamari and Bernier 1989b; Lamari et al. 1991, 1995). However, a cytological investigation showed that the isolates of this race can penetrate wheat epidermal cells and reach mesophyll cells (Lamari et al. 1991). This race has been shown to be rare among many $P$. tritici-repentis collections from wheat (Ali and Francl 2003; Benslimane et al. 2011; Kamel et al. 2019; Lamari and Bernier 1989b; Lamari et al. 1998; Sarova et al. 2005). However, collections from noncereal grasses had a large proportion of race 4 isolates (Ali and Francl 2003). Although race 4 does not produce any known NE and is avirulent to the differentials, it carries toxb, which is $86 \%$ similar to ToxB and can be transcribed at a very low level (Amaike et al. 2008; Martinez et al. 2004).

A collection of $P$. tritici-repentis isolates was obtained from wheat fields in North Dakota to characterize race structure in the state. Race typing on differential lines and molecular characterization has shown that a few isolates are likely race 4 (Z. Liu, unpublished data). Those isolates caused disease on some tetraploid wheat lines in our preliminary evaluations. The objectives of this study were to confirm their race 4 identity, determine their virulence on a set of common wheat and durum cultivars, and map genomic regions conferring resistance/susceptibility to two of these race 4 isolates.

\section{MATERIALS AND METHODS}

Fungal isolates. Five isolates from previous field surveys were initially characterized as race 4 based on the phenotypes they exhibited on tan spot differential lines (Z. Liu, unpublished data).
Those isolates were designated as Ls13-14, Ls13-78, Ls13-86, Ls13-192, and Ls13-198. The first three were collected in the North Dakota counties Mountrail, Kidder, and Wells, respectively, and the last two were collected in Barnes County. Those isolates were subjected to molecular characterization, pathogenicity tests, and genetic mapping of host factors conditioning resistance or susceptibility. Three isolates with known race identity including Pti2 (race 1), 86-124 (race 2), and DW5 (race 5) were used as references in the experiments.

Molecular characterization. The five isolates were first checked for their species identity by sequencing the internal transcribed spacer (ITS) regions. Genomic DNA was extracted according to the protocol described by Shjerve et al. (2014). The PCR amplifications of ITS regions were done using the universal primers ITS4 and ITS5 (Table 1) (White et al. 1990). The PCR amplifications were performed with $10 \mathrm{ng}$ of DNA template in a total volume of $20 \mu \mathrm{l}$ containing $1 \times$ buffer, $200 \mu \mathrm{M}$ dNTPs, $1.5 \mathrm{mM}$ $\mathrm{MgCl}_{2}, 0.5 \mu \mathrm{M}$ of each forward and reverse primer, and $2 \mathrm{U}$ of Bullseye Taq DNA polymerase (MIDSCI, St. Louis, MO). PCRs were performed with the followed cycling conditions: initial denaturation at $95^{\circ} \mathrm{C}$ for 5 min followed by 35 cycles of $95^{\circ} \mathrm{C}$ for $30 \mathrm{~s}, 60^{\circ} \mathrm{C}$ for $30 \mathrm{~s}$, and $72^{\circ} \mathrm{C}$ for $1 \mathrm{~min}$. A final elongation step was performed at $72^{\circ} \mathrm{C}$ for $5 \mathrm{~min}$. PCR products were separated on $1 \%$ agarose gels in $1 \times$ TAE buffer $(0.04 \mathrm{M}$ Tris-acetate, $\mathrm{pH} 8.0$, and 0.001 M EDTA) and purified with PureLink PCR Quick PCR Purification Kit (Invitrogen) following the supplier's recommendation. The purified products were sequenced with the primers IT4 and ITS5 at the facility of Eurofins Genomics USA Inc. (Louisville, $\mathrm{KY}$ ). The obtained sequences were compared with each other and blasted against the NCBI nonredundant database using BLASTn.

After these isolates were confirmed to be $P$. tritici-repentis, they were tested for presence of the ToxA and ToxB genes with published primer pairs (Table 1). Mat1-1-1 was also included as a control for DNA quality and quantity (Ameen et al. 2017). In the PCR amplification, 86-124 (race 2, carrying ToxA) and DW5 (race 5, carrying ToxB) were used as positive controls for the ToxA and ToxB genes, respectively. The obtained PCR products were purified and sequenced as described above. Upon learning that these isolates contain toxb, we downloaded the sequence of a genomic region spanning toxb from GenBank (accession AY083456.2) (Martinez et al. 2004) and designed a new primer pair (toxbF/toxbR) (Table 1) to amplify the full-length tox $b$ open reading frame (ORF) from these isolates. The toxb sequences were aligned with each other as well as the reference toxb sequence using MultAlin program (http:// multalin.toulouse.inra.fr/multalin/).

Plant materials and disease evaluations. The current tan spot differential lines including Salamouni, Glenlea, 6B365, and 6B662 were initially used for race typing. Pathogenicity tests of these isolates were then conducted on a set of thirty wheat lines, the majority of which were hard red spring (HRS) wheat and durum wheat cultivars currently planted in North Dakota (Table 2). Disease evaluations were carried out in the greenhouse and growth chambers under controlled conditions. Seeds of these lines were planted in Super cell cones (Stuewe and Sons, Inc., Corvallis, OR)

TABLE 1 . List of primers used in this study

\begin{tabular}{lllc}
\hline Primers & \multicolumn{1}{c}{ Sequences (from 5' to $3^{\prime}$ ) } & \multicolumn{1}{c}{ Purpose } & Reference \\
\hline PtrPLP2 & CAGAACAAAGGCAGGACTGTGAGC & Amplify the MAT1-1-1 & Lepoint et al. (2010) \\
PtrPLP4 & ATGCGCTCAGCAAGGAAGGTCG & Amplify the ToxA & Andrie et al. (2008) \\
TA51F & GCGTTCTATCCTCGTACTTC & & Andrie et al. (2008) \\
TA52R & GCATTCTCCAATTTCACG & Amplify the ToxB & This study \\
TB71F & GCTACTTGCTGTGGCTATC & Amplify the toxb & White et al. (1990) \\
TB6R & ACGTCCTCCACTTTGCACACTCTC & & \\
toxbF & TGTTTAATCTTATACTAATCCCTTG & Amplify the ITS & \\
toxbR & TCTTGTAGCGCCTAAACTCT & & \\
ITS4 & TCCTCCGCTTATTGATATGC & GGAAGTAAAAGTCGTAACAAGG &
\end{tabular}


with three seeds per cone. The four differential lines mentioned above were also included in the evaluations. Plants were grown in Sunshine SB100 potting mix (Sun Gro Horticulture, Bellevue, WA) with a half teaspoon of the fertilizer Osmocote Plus 15-9-12 (Scotts Sierra Horticultural Product Company, Maysville, $\mathrm{OH}$ ) applied to each cone after planting. The cones were placed onto RL98 racks. The border cones of each rack were planted with the highly susceptible winter wheat cultivar Jerry to reduce the edge effects (Liu et al. 2015). Pathogenicity tests were conducted for four isolates (Ls13-14, Ls13-86, Ls13-192, and Ls13-198) along with Pit2, DW5, and 86-124 used as controls. Ls13-78 did not produce enough spores for pathogenicity test. For this experiment, three biological replications were carried out with a randomized complete block design (RCBD).

To identify genomic regions associated with resistance/ susceptibility to tan spot caused by the race 4 isolates, we conducted disease evaluations of two isolates (Ls13-14 and Ls13-192) on two tetraploid populations. The first population was derived from the cross between Ben (sensitive to Ptr ToxA) and PI 41025 and referred as BP025, which consisted of 200 recombinant inbred lines (RILs) (Zhang et al. 2014). Ben is a North Dakota hard amber durum variety released in 1998 (Elias and Miller 1998), and PI 41025 is a cultivated emmer wheat (T. turgidium ssp. dicoccum) accession collected near Samara, Russia. The second population, referred to as RP336, was derived from a cross between the durum line Rusty (sensitive to Ptr ToxB) and the tetraploid wheat T. turgidum ssp. turgidum accession PI 387336, which consisted of 186 RILs (Liu et al. 2020a). In this experiment, disease evaluations included all the
RILs and their parental lines from each population as well as the four differential lines. Three biological replications were included with an RCBD arrangement. The planting and growing plants followed the same procedures as described above.

The fungal culturing, inoculum preparation and inoculation methods followed standard protocols described in Liu et al. (2015). Briefly, the fungus was grown on V8 potato dextran agar medium for 5 days under dark followed by mycelium flattening and a lightdark incubation cycle. Conidia were washed with sterilized distilled water from the culture plates to make spore suspension. The spore concentration was adjusted to approximately $3,000 \mathrm{spores} / \mathrm{ml}$ and two drops per $100 \mathrm{ml}$ of the surfactant reagent Tween 20 were added before inoculation. Plants at the two- to three-leaf stage were inoculated using an air-pressured spray gun. After inoculation, plants were kept in a mist chamber with $100 \%$ humidity for $24 \mathrm{~h}$. Then, the plants were transferred to a growth chamber with a 12-h photoperiod at $21^{\circ} \mathrm{C}$. Disease reactions were scored at 7 days postinoculation using a 1 to 5 rating scale described by Lamari and Bernier (1989a). We added 0 to the scale when no obvious reaction was observed. Disease scores lower than 2.0 were considered resistant.

Statistical analysis. In pathogenicity tests, the disease mean difference between durum and common wheat groups was analyzed using the Wilcoxon test in PROC NON-PARAMETRIC in SAS 9.4 Software (SAS Institute, Cary, NC, 2016). After the disease data were obtained for the two populations, normality of the disease data for each isolate/replication was evaluated using the Shapiro-Wilk test in PROC UNIVARIATE in SAS 9.4 Software (SAS Institute,

TABLE 2. Reaction of wheat genotypes to tan spot caused by different Pyrenophora tritici-repentis race/isolate

\begin{tabular}{|c|c|c|c|c|c|c|c|c|c|c|}
\hline \multirow[b]{2}{*}{ Wheat type } & \multirow[b]{2}{*}{ Genotypes } & \multirow[b]{2}{*}{ Agent or origin ${ }^{a}$} & \multirow[b]{2}{*}{ Year released } & \multicolumn{4}{|c|}{ Race $4^{b}$} & \multirow{2}{*}{$\frac{\text { Race } 5^{b}}{\text { DW5 }}$} & \multirow{2}{*}{$\frac{\text { Race } 1^{b}}{\text { Pti2 }}$} & \multirow{2}{*}{$\frac{\text { Race } 2^{b}}{86-124}$} \\
\hline & & & & Ls13-14 & Ls13-192 & Ls13-86 & Ls13-198 & & & \\
\hline Common wheat & Barlow & ND & 2009 & 0.3 & 0.3 & 0.8 & 0.0 & 3.8 & 4.5 & 2.0 \\
\hline Common wheat & Brennan & AgriPro & 2009 & 0.3 & 0.4 & 0.5 & 0.5 & 1.5 & 3.0 & 2.0 \\
\hline Common wheat & Glenn & ND & 2005 & 0.3 & 0.9 & 0.5 & 0.0 & 4.0 & 3.0 & 2.5 \\
\hline Common wheat & Howard & ND & 2000 & 0.3 & 0.7 & 0.3 & 0.0 & 3.5 & 4.0 & 3.0 \\
\hline Common wheat & Jenna & AgriPro & 2009 & 0.2 & 0.4 & 0.0 & 0.0 & 1.0 & 2.5 & 1.5 \\
\hline Common wheat & Kelby & AgriPro & 2006 & 0.2 & 0.8 & 0.5 & 0.0 & 2.5 & 2.5 & 2.0 \\
\hline Common wheat & Mott & ND & 2007 & 0.8 & 1.3 & 0.8 & 1.0 & 3.0 & 3.5 & 3.5 \\
\hline Common wheat & Prosper & ND & 2011 & 0.5 & 0.6 & 0.3 & 0.0 & 4.0 & 4.0 & 3.0 \\
\hline Common wheat & RB07 & $\mathrm{MN}$ & 2007 & 0.2 & 0.5 & 0.3 & 0.0 & 2.0 & 2.5 & 1.5 \\
\hline Common wheat & Rollag & $\mathrm{MN}$ & 2011 & 0.0 & 0.5 & 0.8 & 0.0 & 4.5 & 2.8 & 3.0 \\
\hline Common wheat & Select & $\mathrm{SD}$ & 2010 & 0.2 & 0.9 & 0.8 & 0.3 & 4.3 & 4.5 & 2.5 \\
\hline Common wheat & Steele-ND & ND & 2004 & 0.5 & 1.0 & 0.5 & 0.3 & 4.3 & 3.5 & 3.5 \\
\hline Common wheat & SY Soren & Syngenta/AgriPro & 2011 & 0.2 & 0.6 & 0.5 & 0.5 & 2.5 & 1.8 & 1.0 \\
\hline Common wheat & SY Tyra & Syngenta/AgriPro & 2011 & 0.0 & 0.7 & 0.3 & 0.0 & 1.8 & 3.5 & 1.0 \\
\hline Common wheat & Velva & ND & 2011 & 0.2 & 0.8 & 0.0 & 0.0 & 3.3 & 2.3 & 1.0 \\
\hline Common wheat & Chinese spring & China & - & 0.3 & 0.3 & 0.5 & 0.0 & 1.8 & 2.0 & 5.0 \\
\hline Common wheat & Vantage & WestBred & 2007 & 0.2 & 1.0 & 1.3 & 0.3 & 2.0 & 3.5 & 2.0 \\
\hline Common wheat & Briggs & SD & 2002 & 0.2 & 0.6 & 0.5 & 0.0 & 2.0 & 3.5 & 3.0 \\
\hline \multicolumn{4}{|c|}{ Means for common wheat } & 0.3 & 0.7 & 0.5 & 0.2 & 2.9 & 3.2 & 2.4 \\
\hline Durum wheat & Alkabo & ND & 2005 & 0.5 & 1.5 & 1.0 & 1.8 & 2.5 & 1.8 & 2.0 \\
\hline Durum wheat & Ben & ND & 1996 & 3.8 & 3.4 & 3.3 & 2.8 & 4.5 & 3.0 & 4.0 \\
\hline Durum wheat & Carpio & ND & 2012 & 2.5 & 2.2 & 0.5 & 2.0 & 3.5 & 2.8 & 2.5 \\
\hline Durum wheat & Dilse & ND & 2002 & 3.5 & 3.3 & 3.3 & 3.0 & 3.8 & 2.5 & 3.5 \\
\hline Durum wheat & Divide & ND & 1994 & 3.0 & 3.1 & 2.3 & 2.8 & 4.5 & 2.0 & 3.5 \\
\hline Durum wheat & Grenora & ND & 2006 & 3.2 & 3.2 & 2.5 & 2.8 & 4.0 & 3.5 & 3.0 \\
\hline Durum wheat & Lebsock & ND & 1999 & 3.3 & 3.3 & 2.8 & 3.0 & 4.5 & 2.0 & 2.5 \\
\hline Durum wheat & Langdon & ND & 1956 & 1.7 & 2.4 & 0.8 & 1.8 & 4.5 & 4.5 & 4.0 \\
\hline Durum wheat & Mountrail & ND & 1998 & 2.5 & 3.0 & 1.5 & 2.0 & 4.5 & 1.5 & 3.0 \\
\hline Durum wheat & Pierce & ND & 2001 & 3.2 & 3.1 & 2.5 & 2.8 & 4.5 & 2.0 & 4.0 \\
\hline Durum wheat & Rusty & ND & 2004 & 1.5 & 1.7 & 1.0 & 0.0 & 4.5 & 1.5 & 2.5 \\
\hline Durum wheat & Tioga & ND & 2010 & 3.3 & 2.6 & 2.5 & 3.0 & 4.0 & 2.0 & 2.5 \\
\hline Emmer wheat & PI 41025 & Russia & - & 1.2 & 0.5 & - & - & - & - & - \\
\hline Poulard wheat & PI 387336 & Ethiopia & - & 3.3 & 3.2 & - & - & - & - & - \\
\hline \multicolumn{4}{|c|}{ Means for tetraploid wheat } & 2.6 & 2.6 & 2 & 2.3 & 4.1 & 2.4 & 3.1 \\
\hline \multicolumn{4}{|c|}{ Mean difference between common wheat and durum groups $P>|\mathrm{t}|^{\mathrm{c}}$} & $<0.0001$ & $<0.0001$ & $<0.0001$ & $<0.0001$ & $<0.0001$ & 0.0163 & 0.001 \\
\hline
\end{tabular}


2016). If the data fit a normal distribution, it was tested for homogeneity using Bartlett's $\chi^{2}$ test (Snedecor and Cochran 1989). If the data did not fit a normal distribution, Levene's test was used to test the homogeneity among different replicates (Levene 1960). The data from homogeneous replications were combined and the means were used for quantitative trait locus (QTL) analysis.

QTL analysis. QTL analysis employed the genetic linkage maps of the two populations that have been published previously (Liu et al. 2020a, b). BP025 was genotyped several times through different methods including simple sequence repeats (SSRs), Illumina iSelect 9K SNPs array, and genotyping-by-sequencing (GBS). The genetic linkage map for this population contained a total of 4,883 markers (96 SSRs, 878 9k, and 3,909 GBS) with a total length of 4,749.6 cM covering all 14 chromosomes. The genetic map of the RP336 population contained 2,894 GBS markers and had a total length of $2,858 \mathrm{cM}$ covering all 14 chromosomes. QTL mapping was conducted using QGene 4.4.0 (Joehanes and Nelson 2008). Composite interval mapping (CIM) performed with forward

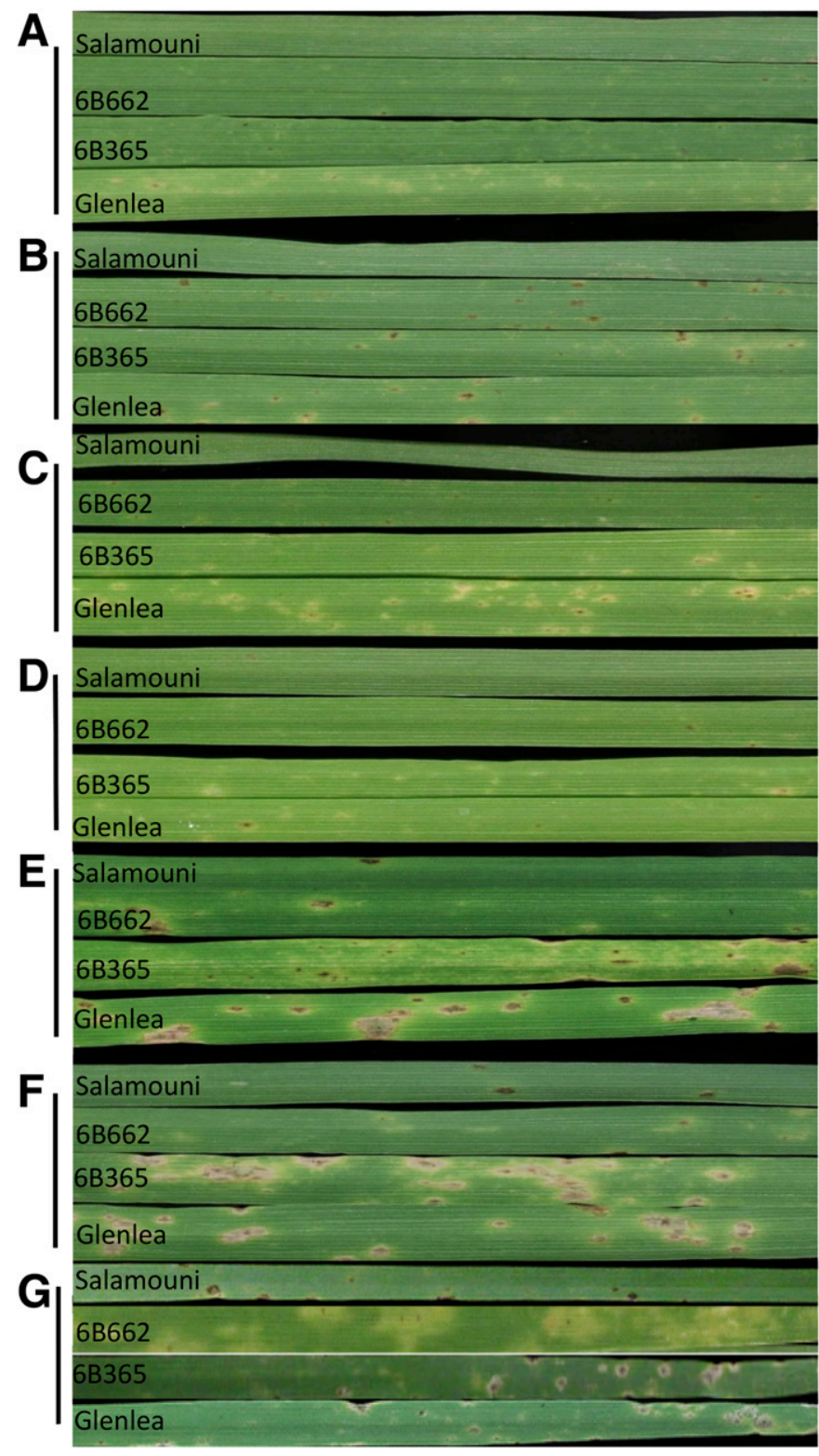

Fig. 1. Reaction of wheat differential lines to tan spot caused by Pyrenophora tritici-repentis race 4 isolates and other known races. A, Ls13-192; B, Ls1386; C, Ls13-14; D, Ls13-198; E, Pti2 (race 1); F, 86-124 (race 2); and G, DW5 (race 5). cofactors selection was used to identify the genomic region associated with tan spot reaction and to quantify the disease variations explained by the QTL $\left(R^{2}\right)$. A permutation test with 1,000 iterations resulted in a logarithm of the odds (LOD) threshold of 4.2 for an experiment-wise significance level of 0.05 . To find out whether the QTLs detected in this study possibly represent known genes or genetic loci, the physical positions and the markers linked were compared. The physical locations of markers were obtained using marker sequences as queries in BLASTn searches of the IWGSC Chinese Spring reference genome (v1.0).

\section{RESULTS}

Species and race confirmation. Inoculation of all four isolates (Ls13-14, Ls13-86, Ls13-192, and Ls13-198) on four differentials (Salamouni, 6B662, 6B365, and Glenlea) produced no or little disease. Most reactions were pin-sized black dots either alone or surrounded by small amounts of chlorosis (Fig. 1). Almost no reaction could be seen on the resistant line Salamouni. However, the three control isolates Pti2 (race 1), DW5 (race 5), and 86-124 (race 2) caused a large amount of necrosis or chlorosis on their differential lines. These results indicated that the four Ls 13 isolates belonged to race 4 .

A partial ITS sequence ( $436 \mathrm{bp}$ ) was obtained for all five isolates after removal of low-quality base readings. The ITS sequences were identical for all five isolates. BLASTn searches showed that these sequences were $100 \%$ identical to the published ITS sequences of P. tritici-repentis strains 90-2T (AM887495) (Lepoint et al. 2010), 90-2 (EF452479) (Andrie et al. 2008), and SY3-122 (AY739819) (Friesen et al. 2005), all of which were characterized as $P$. triticirepentis race 4 . The partial ITS sequences for all five isolates have been deposited as GenBank accession numbers MN855580 to MN855584.

All isolates lacked the ToxA gene, but they produced weak amplification with a band size of approximate $250 \mathrm{bp}$ using the toxb primer set TB71F/TB6R (Fig. 2). The fragments were sequenced and confirmed to be the tox $b$ sequence. Using a new pair of primers (toxbF and toxbR) (Table 1), we amplified the full-length fragment of the tox $b$ gene from all five isolates. Sequence analysis indicated that the toxb ORF (267 bp) was identical among all five isolates) and

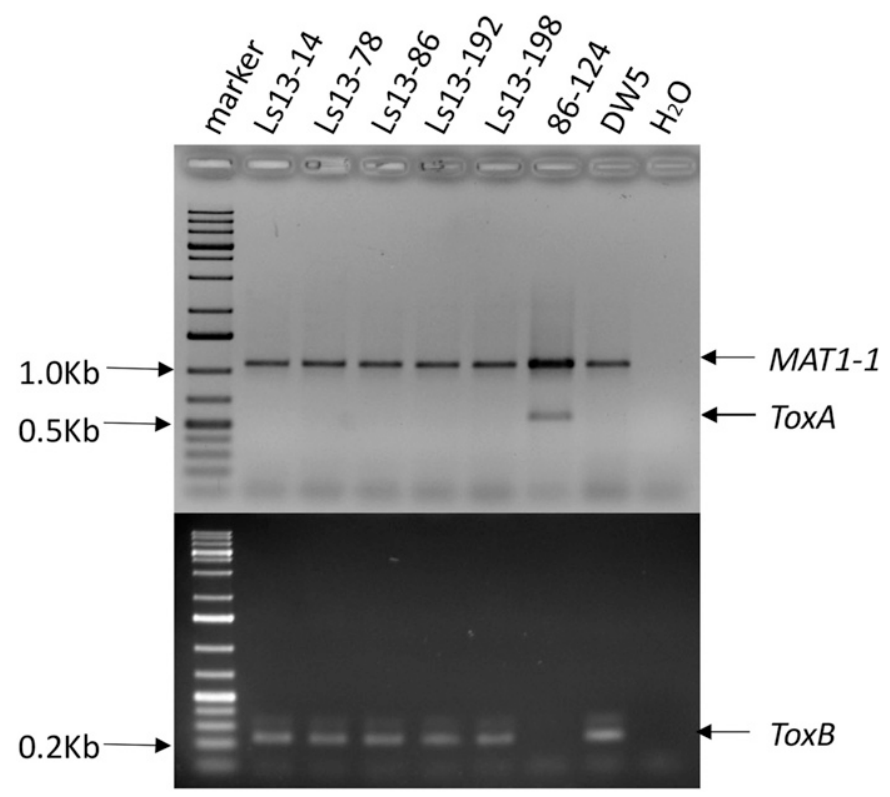

Fig. 2. PCR testing of the presence of the ToxA and ToxB genes in race 4 isolates. ToxA was multiplexed with MAT1-1. Isolates 86-124, DW5, and $\mathrm{H}_{2} \mathrm{O}$ were included in the PCR as controls. Arrows indicate size of DNA markers and the individual bands. 
have been deposited in NCBI GenBank (MN864562 to MN864566). BLASTn analysis using the full-length sequence indicated that the toxb sequence of these five isolates was $100 \%$ identical to that of race 4 isolate SD20 (AY083456.2) (Martinez et al. 2004), and 99\% identical to that of race 4 isolate 90-2 (AF483832) (Strelkov and Lamari 2003). The sequence was $87 \%$ similar to the ToxB gene sequence from the race 5 isolate DW7 (AY425484) (Martinez et al. 2004). Therefore, these results further confirmed that these isolates are race 4 .

Pathogenicity tests. The results of pathogenicity test of four isolates on thirty wheat lines are shown in Table 2. All HRS wheat cultivars had disease means less than 1.0 for all four isolates indicating nonpathogenic or avirulent reactions of these race 4 isolates on common wheat genotypes. The average disease rating was 0.26 for Ls13-14, 0.68 for Ls13-192, 0.49 for Ls13-86, and 0.15 for Ls13-198. Most HRS wheat cultivars developed no visible symptom or black pinpoint lesions on the leaves, e.g., Jenna, Steele-ND, and Vantage, whereas other cultivars such as Mott and Prosper developed small and restricted necrotic lesions (Fig. 3). For the reference isolates Pti2, DW5, or 86-124, all HRS cultivars except Jenna and SY Soren showed highly susceptible or susceptible reactions.

For tetraploid wheat, the disease means ranged from 0.5 (e.g., Ls13-14 on Alkabo) to 3.8 (Ls13-14 on Ben), indicating variable reactions to these race 4 isolates (Table 2). Some of the reactions were characterized as being susceptible because their disease means were greater than 3.0. The average disease ratings were 2.66 for Ls13-14, 2.73 for Ls13-192, 1.98 for Ls13-86, and 2.29 for Ls13198. The disease reactions were observed as large necrotic lesions surrounded by yellow margin on highly susceptible lines (Fig. 3). This indicates that these race 4 isolates can cause disease on some tetraploid genotypes. For reaction to the reference isolates, most of durum cultivars were highly susceptible to DW5 (race 5), but less susceptible to race 1 and 2 isolates.

Comparison of disease ratings between tetraploid and hexaploid wheat groups found they differ significantly difference in reaction to race 4 isolates as well as race 1, 2, and 5 isolates (Table 2).

QTL identification. Based on the results from pathogenicity tests, Ben and PI 41025 as well as Rusty and PI 387336 differed greatly in reaction to the four race 4 isolates we identified (Table 2, Fig. 3). Therefore, the BP025 and RP336 populations were used to identify genomic regions associated with reaction to tan spot caused by the race 4 isolates Ls13-14 and Ls13-192 on each population. Normality tests rejected a normal distribution of the disease reaction to both isolates $(P<0.05)$. Homogeneity analysis indicated that the variance among the replicates for each isolate were not significant $(P=0.12$ to 0.44$)$. Therefore, the means of three biological replicates for each isolate were used in subsequent data analysis and QTL identification. Both populations segregated for reaction to the two isolates, exhibiting a range from highly resistant to highly susceptible reactions, and no obvious transgressive segregation was observed (Fig. 4). The majority of RILs in BP population had disease scores lower than 3.0 while the RP336 population skewed to susceptible reaction.

Six QTLs were identified in BP025 with three for each isolate (Table 3). The QTLs were distributed on chromosomes 1A (designated as BP-ls192-1A and BP-ls14-1A), 4B (BP-ls192-4B and $B P-l s 14-4 B)$ and $5 A(B P-l s 192-5 A$ and $B P-l s 14-5 A)$ (Fig. 5, Table 3). The resistance alleles for all the QTLs were contributed by PI 41025. The LOD values for these QTLs ranged from 4.8 to 13.0 and they explained from 11 to $26 \%$ of the variation in disease. The 5A QTL for two isolates (BP-ls192-5A and BP-ls14-5A) colocalized to the same physical interval $(660$ to $672 \mathrm{Mb})$, whereas the $1 \mathrm{~A}$ and 4B QTLs for the two isolates were located to different intervals. The 5A and 4B QTLs had slightly higher effect on disease compared with the 1A QTL (Table 3).

For the RP336 population, two QTLs (RP-ls192-5A and $R P$ $l s 192-4 B)$ were identified for Ls13-192 and one (RP-ls14-5A) for Ls13-14 (Table 3, Fig. 5). RP-ls192-5A and RP-ls14-5A were located at the same physical interval and explained a large portion of disease variations. This 5A QTL is most likely the same as the one identified in the BP025 population according to the physical locations of flanking markers. However, the 4B QTL was in a different physical interval compared with the ones identified in the BP025 population.

\section{DISCUSSION}

P. tritici-repentis isolates are classified into eight races according to their virulence on a set of wheat lines, including four common wheat and two durum lines, with race 4 being avirulent to all those lines (Aboukhaddour et al. 2013; Lamari and Strelkov 2010). So far, many studies have reported the identification of race 4 isolates from wheat and alternative hosts (Abdullah et al. 2017a, b; Ali and Francl 2003; Benslimane et al. 2011; Friesen et al. 2005; Kamel et al. 2019; Lamari et al. 1995, 1998, 2005; Singh et al. 2007). Little attention has been paid to race 4 isolates because they were assumed to be avirulent to all wheat lines. It has been an intriguing question as to why race 4 exists in nature without causing disease. In this work, we confirmed the race 4 identity of five isolates collected from North Dakota using pathogenicity tests and molecular characterization. Although these isolates were avirulent to all common wheat lines tested, they caused disease on some durum cultivars and other tetraploid wheat genotypes. Using two segregating tetraploid

A

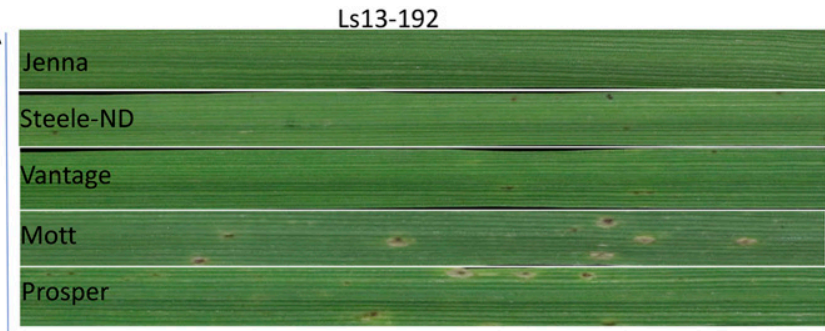

B

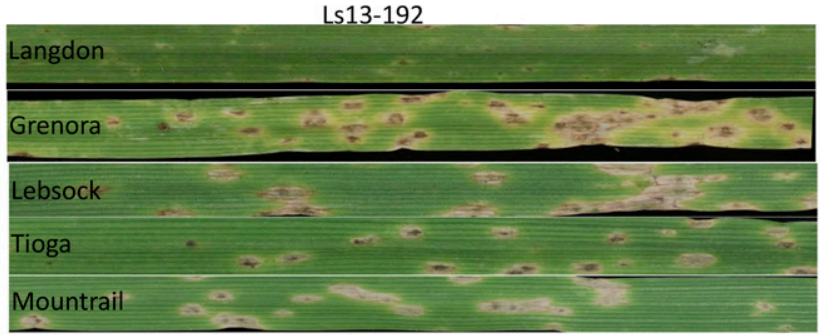

C

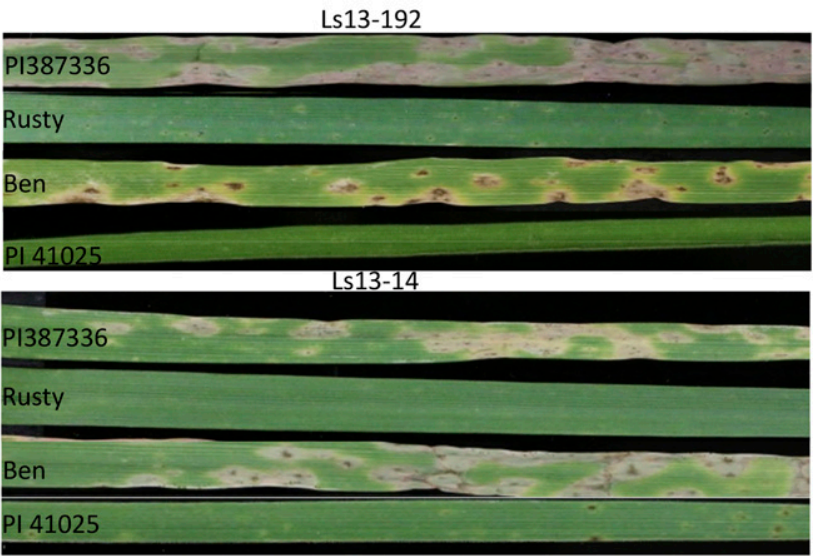

Fig. 3. Reaction of representative wheat lines to fungal inoculation with race 4 isolates. A, Common wheat lines inoculated with Ls13-192. B, Durum wheat lines inoculated with LS13-192. C, The parental lines for two tetraploid population inoculated with Ls13-192 and Ls13-14. Disease scores for all wheat genotypes to different Pyrenophora tritici-repentis race/isolates are listed in Table 2. 
populations, we further showed that there are several genomic regions in wheat that govern reaction to these race 4 isolates. Benslimane (2018) reported five isolates that caused no disease on common wheat, but on durum lines. However, these isolates were not considered to be race 4 because they carry both ToxA and ToxB and no toxb. The study speculated that Ptr ToxA and Ptr ToxB were not expressed for some reasons. Therefore, our study was the first to show that race 4 isolates cause disease on durum cultivars and other tetraploids. This might provide an explanation for why race 4 can be consistently isolated from infected wheat leaves and is present in nature. Our finding also suggests that durum breeding programs should include race 4 isolates in their disease screenings. Because common wheat and durum have shown many differences in reaction to different $P$. tritici-repentis races, it might be necessary to take different approaches in the breeding of tan spot resistance for two different types of wheats.

The five race 4 isolates used in this study were obtained from a collection of 352 isolates obtained from North Dakota wheat fields (Z. Liu, unpublished data). Unfortunately, we did not record the wheat type or cultivar they were collected from; thus, it remains unknown if they were collected from durum wheat. Previous studies have shown that race 4 can be isolated at low percentages ( 4 to 20\%) from bread wheat (Abdullah et al. 2017b; Ali and Francl 2003; Lamari et al. 1991, 1995, 1998) and at high percentages (40 to 98\%) from alternative hosts such as noncereal grasses and rye (Abdullah et al. 2017a; Ali and Francl 2003). There were also reports of race 4 being occasionally isolated from durum wheat (Benslimane et al. 2011; Kamel et al. 2019). It would be important to examine if the previously reported race 4 isolates from other geographic regions and hosts are virulent on durum. Further research is needed to systematically investigate the race structure of the fungal populations collected from durum and how prevalent race 4 is in durum wheat production areas. All such information will be important for durum wheat breeding programs. In addition, we observed that our race 4 isolates caused small necrotic lesions on some common wheat cultivars, and thus it is important to test these race 4 isolates on a wider range of common wheat cultivars.

Although $P$. tritici-repentis has eight races described, the genetic and evolutionary relationship among them remains unclear. According to Hosford (1982) and Maraite (1997), the fungus was first isolated from quack grass (Agropyrum repens, originally called Triticum repens) in 1903 and then from wheat in 1928. Before the 1940s, the fungus was described as a saprophyte or minor pathogen on wheat, but after that it became a highly virulent pathogen on wheat, probably through acquisition of the NE gene ToxA (Friesen et al. 2006). Our speculation is that the fungus first appeared on wheat as race 4 and later evolved into other virulent races by acquiring different virulence genes. Population genetic studies have revealed a clear genetic separation of race 4 from all other virulent isolates (Aboukhaddour et al. 2011; Aung 2001). This genetic separation was also supported by a recent whole genome phylogenetic analysis (Moolhuijzen et al. 2018). Considering that wheat evolved from tetraploid to hexaploid levels, it is possible that race 4 gained virulence first on tetraploid wheat by obtaining the ToxB, ToxC, and other unknown virulence genes, and then on hexaploid wheat by acquiring the ToxA gene. This speculation can be supported by several lines of evidence: (i) highly similarly homologs of ToxB were identified from the related grass pathogen $P$. bromi and large percentage of race 4 could be isolated from the grasses (Ali and Francl 2003; Andrie et al. 2008; Andrie and

\section{BP025}

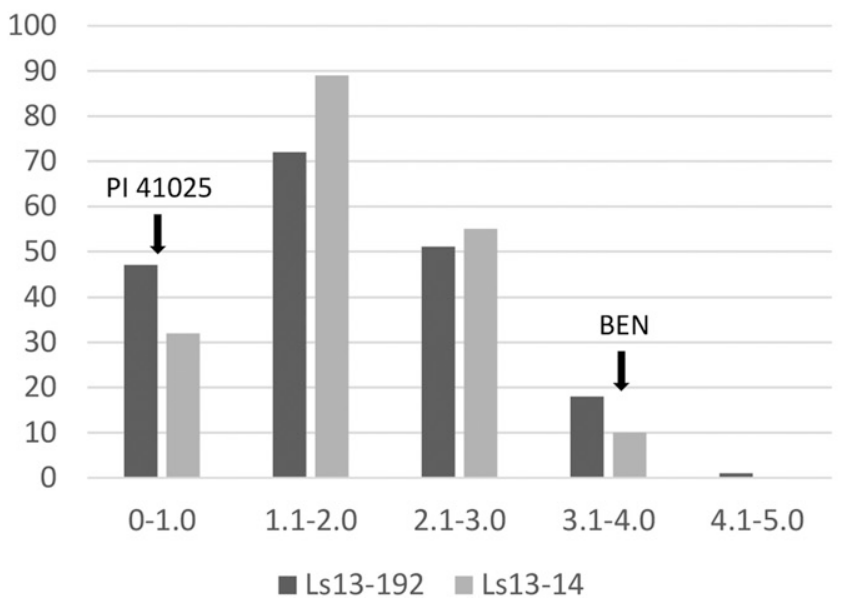

RP336

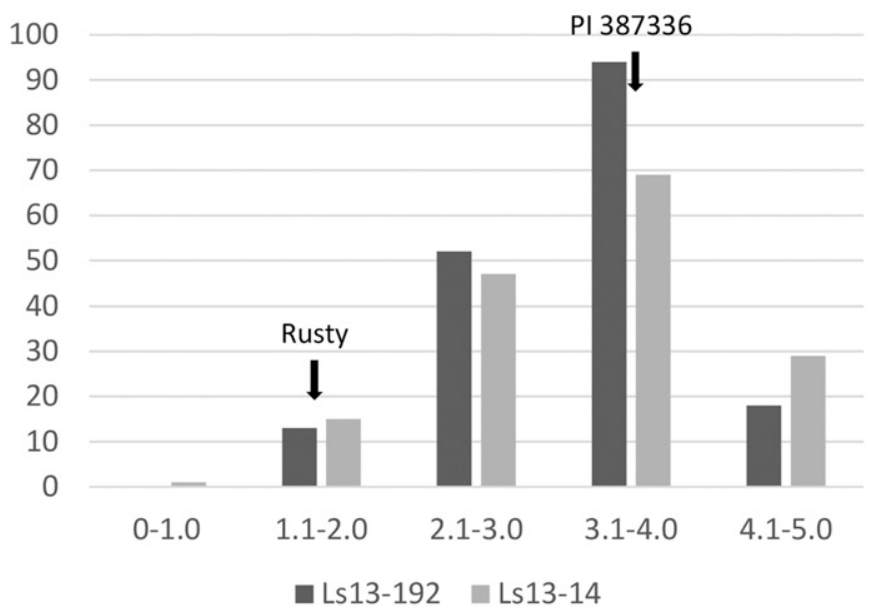

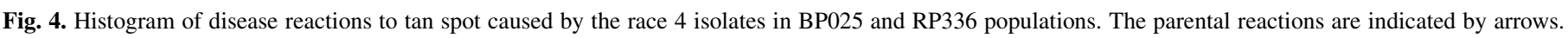

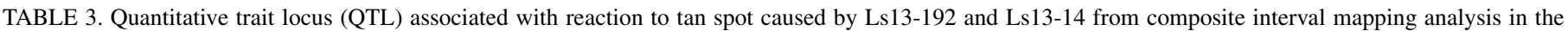
BP025 and RP336 population

\begin{tabular}{|c|c|c|c|c|c|c|c|}
\hline Population & Isolate & QTL & Genetic interval (cM) & Physical interval (Mbp) & $\mathrm{LOD}^{\mathrm{a}}$ & $R^{2}(\%)^{\mathrm{b}}$ & Flanking markers \\
\hline \multirow[t]{6}{*}{$\mathrm{BP} 025$} & Ls13-192 & BP-ls 192-1A & $92-96$ & $51-56$ & 4.8 & 0.11 & S1A_56880271-S1A_51221934 \\
\hline & & $B P-l s 192-4 B$ & $58-60$ & $53-106$ & 13 & 0.26 & S4B_53863164-S4B_106853468 \\
\hline & & $B P-l s 192-5 A$ & $408-410$ & $668-672$ & 7.6 & 0.17 & S5A_668189084-S5A_672505022 \\
\hline & Ls13-14 & $B P-l s 14-1 A$ & $118-120$ & $168-299$ & 5.8 & 0.13 & S1A_168577107-S1A_299657544 \\
\hline & & $B P-l s 14-4 B$ & $110-114$ & $535-563$ & 6.2 & 0.14 & $S 4 B \_535050204-S 4 B \_563205252$ \\
\hline & & $B P-l s 14-5 A$ & $404-408$ & $666-670$ & 11.6 & 0.25 & S5A_666689644-S5A_670630031 \\
\hline \multirow[t]{3}{*}{ RP336 } & Ls13-192 & $R P-l s 192-4 B$ & $60-64$ & $621-639$ & 6.2 & 0.15 & 4B_621667742-4B_639997885 \\
\hline & & $R P-l s 192-5 A$ & $236-238$ & $666-674$ & 19.8 & 0.41 & 5A_666503690-5A_674124822 \\
\hline & Ls13-14 & $R P-l s 14-5 A$ & $236-238$ & $666-674$ & 17.2 & 0.39 & 5A_666503690-5A_674124822 \\
\hline
\end{tabular}

a Permutation test with 1,000 iterations yielded a logarithm of the odds (LOD) value of 4.2 and it was used as the cut-off to identify significant QTL.

b $R^{2}$ value indicates the amount of phenotypic variation explained by the individual QTL. 
Ciuffetti 2011); (ii) P. tritici-repentis races 3 and 5, which produce the individual NEs Ptr ToxC and Ptr ToxB, respectively, were mostly isolated from durum wheat (Ali and Francl 2003; Kamel et al. 2019; Lamari and Bernier 1989b; Lamari et al. 2005); and (iii) The Ptr ToxB-Tsc2 and Ptr ToxC-Tscl interactions play important roles in disease on both tetraploid wheat and common wheat whereas Ptr ToxA-Tsn1 interaction is only important for common wheat, i.e., the ToxA gene acts as a virulence factor on hexaploid but not tetraploid wheat (Faris et al. 2012, 2020; Galagedara et al. 2020; Liu et al. 2020a, b; Virdi et al. 2016). There are numerous subspecies of tetraploid wheat, which have longer and more complex evolutionary and domestication histories than hexaploid wheat. Determining the pathogenicity or virulence of race 4 isolates on different tetraploid subspecies might provide a better picture of the evolution of $P$. tritici-repentis races. In addition, the D genome progenitor Aegilops tauchii may play a role in $P$. tritici-repentis evolution because susceptibility has been reported in some accessions (Alam and Gustafson 1988; Friesen et al. 2008).

As mentioned, the current race classification system for $P$. triticirepentis is largely based on the ability of the isolate to produce one or more of the three NEs, and the wheat lines with sensitivity to each of the three NEs serve as the differential set. Therefore, this system only allows the description of eight races (23) (Lamari et al. 2003). The limitation of the current race classification system was demonstrated by the fact either that the existing races produced additional virulence factors or that some isolates with no production of all three NEs caused disease on one of the differential lines (Ali et al. 2010; Friesen et al. 2003; Gamba and Lamari 1998; Guo et al. 2018; Kamel et al. 2019; Lamari et al. 1995). Our research further indicates there is a need to revise the current classification system by adding durum and other tetraploid wheat, which has been suggested by previous studies (Lamari and Bernier 1991; Singh et al. 2007). Here, we showed that at least some race 4 isolates can cause disease on tetraploid wheat; therefore, the susceptible tetraploid wheat lines, such as Ben and PI 387336, are suggested to be included in the differential set. However, adding more differential lines would significantly increase the number of races, which would make disease system difficult to study and follow. The expansion of the race classification system should rely on further dissection of the genetics of host-pathogen interactions in both hexaploid and tetraploid wheats. The development of differential lines with individual susceptibility factors would be useful to describe and encompass all possible races.

Although race 4 is nonpathogenic, most race 4 isolates have been reported to carry toxb, which is $87 \%$ homologous to ToxB (Martinez et al. 2004; Strelkov et al. 2006). ToxB encodes Ptr ToxB, a chlorosis-inducing protein, and is present and highly expressed in isolates of races $5,6,7$, and 8 . The copy number, gene sequence and

$\begin{array}{llll}\text { Mbp } & \text { 1A } & \text { 4B }\end{array}$

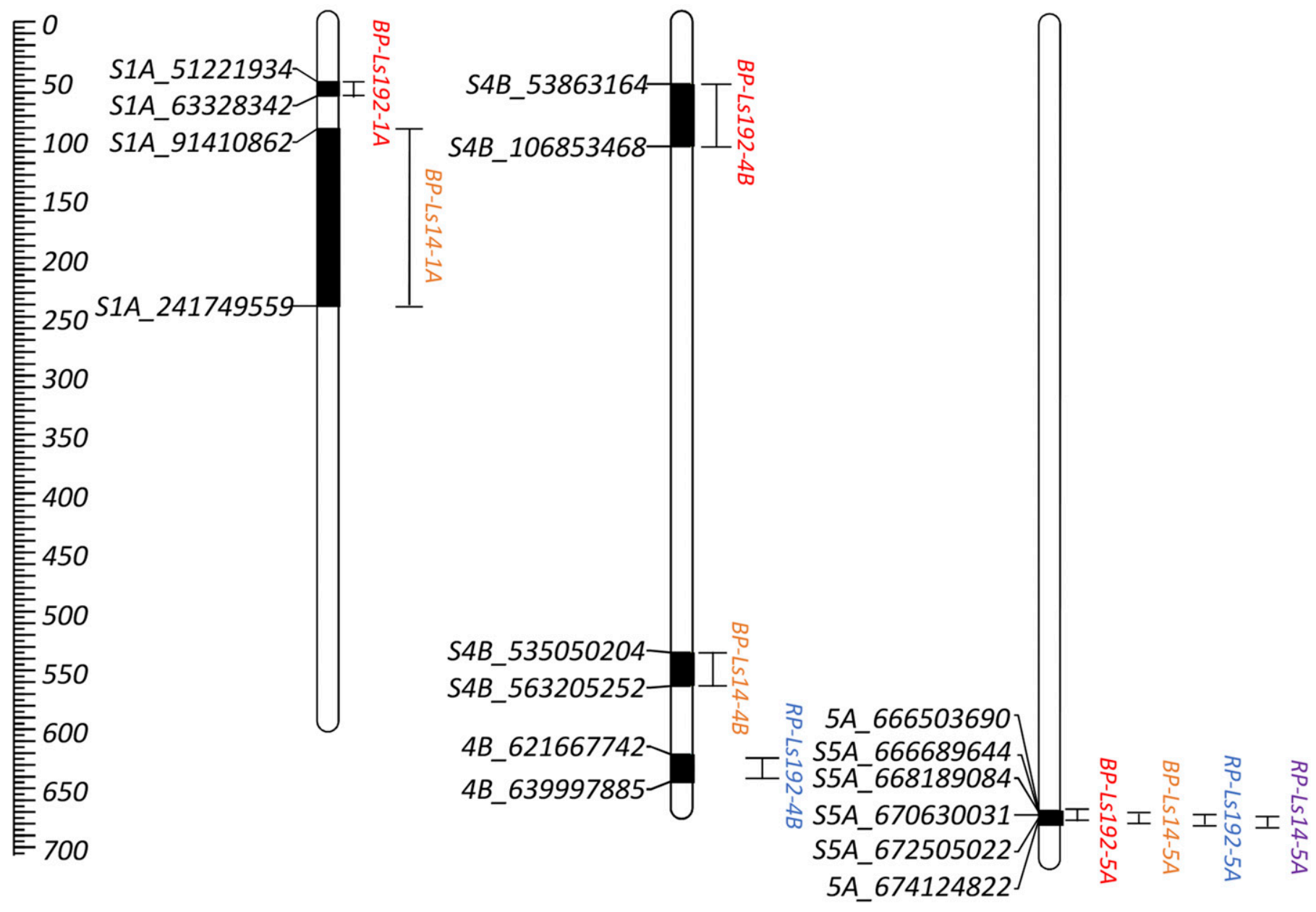

Fig. 5. The genomic regions identified by quantitative trait locus (QTL) associated the development of tan spot disease caused by the race 4 isolates Ls13-192 and Ls13-14. A physical scale in mega base pairs for wheat chromosomes is shown to the left. The solid black box on each chromosome indicates the region significantly associated with tan spot on different population and caused by different isolate. Markers on the left of each chromosome define the physical region of the QTL. The QTLs are listed to the right of the chromosomes, with different colors for population and isolate combinations, including BP025 with Ls13-192 (red), BP025 with Ls13-14 (orange), RP336 with Ls13-192 (blue), and RP336 with Ls13-14 (purple). The LOD and $R^{2}$ values for each QTL are presented in Table 3. 
role in virulence for ToxB has been extensively investigated (Ciuffetti et al. 2010). However, there were only two toxb ORF sequences available in NCBI GenBank, SD20 and 90-2, which were collected in the United States (South Dakota) and Canada, respectively (Martinez et al. 2004; Strelkov and Lamari 2003). The toxb gene was also shown to be expressed in mycelium tissues and conidia of 90-2 (Amaike et al. 2008; Martinez et al. 2004; Strelkov et al. 2006). The race 4 isolates we collected in North Dakota all carry identical toxb sequences, which were identical to that of SD20 but slightly different (99\% homology) from 90-2. We did not measure the expression of toxb for the ND isolates, but it would be an interesting to determine if toxb functions in virulence on these tetraploid wheat genotypes.

To verify virulence of the race 4 isolates, we inoculated two of these isolates (Ls13-192 and Ls13-14) onto two segregating tetraploid wheat populations (BP025 and RP336) and identified wheat genomic regions conferring resistance or susceptibility to them using QTL mapping. In total, we identified six genomic regions distributed on chromosomes $1 \mathrm{~A}, 4 \mathrm{~B}$, and 5A (Table 3, Fig. $5)$. Among them, the genomic region on chromosome $5 \mathrm{~A}$ was identified for both isolates and populations indicating a common QTL in tetraploid wheat associated with reaction to race 4 isolates. Several regions on chromosome $5 \mathrm{~A}$ have been previously identified to harbor tan spot resistance or susceptibility QTL on both hexaploid and tetraploid wheat with virulent races (Chu et al. 2008, 2010; Hu et al. 2019; Kariyawasam et al. 2016; Liu et al. 2020a; Virdi et al. 2016). Our 5A QTL was physically located within 666.5 to $674.1 \mathrm{Mbp}$, which likely corresponds to the region for QTs.fcu-5A.2, RP336_86-124_5A.2, RP696_86-124_5A.2, and RP336_86-124 DToxA_5A (Chu et al. 2010; Liu et al. 2020a). These QTLs were identified with races 1 and 2 or their ToxA knockout strains. This suggests that race 4 isolates might carry the same virulence factor as other virulent races that interact with this $5 \mathrm{~A}$ QTL to cause disease.

Three genomic regions on $4 \mathrm{~B}$ were identified with one $(B P$ $l s 192-4 B)$ on the short arm and the other two (BP-ls $14-4 B$ and $R P$ $l s 192-4 B)$ on the long arm, and they were specific to an individual population or isolate. No tan spot-associated QTL has previously been reported on 4B in hexaploid wheat, but Virdi et al. (2016) identified a QTL $(Q T s . f c u-4 B)$ on $4 \mathrm{BS}$ in a tetraploid wheat associated with disease caused by both L13-35 (race 2) and DW5 (race 5). This QTL might be in proximity of the QTL BP-ls 192-4B identified in this research. However, the two QTLs on 4BL seem to be novel. Two closely linked regions on chromosome $1 \mathrm{~A}$ were identified in the BP025 population, but not in RP336 suggesting this QTL might be host specific. Many QTLs have been identified on 1AS for tan spot resistance or susceptibility, but they are mainly associated with disease attributed to the Ptr ToxC-Tscl interaction (Faris et al. 2013; Kariyawasam et al. 2016; Liu et al. 2017). However, race 4 does not produce Ptr ToxC and the physical location for $T s c 1$ tends to be more distal end of chromosome 1A (Liu et al. 2020b). Thus, these QTLs identified here unlikely correspond to the Tscl locus and are also novel. The identification of novel QTL suggests that these race 4 isolates carry unidentified and unique virulence factor(s) to cause disease on tetraploid wheat genotypes.

\section{ACKNOWLEDGMENTS}

We thank Kishore Chittem for assistance in statistical analysis.

\section{LITERATURE CITED}

Abdullah, S., Sehgal, S. K., Ali, S., Liatukas, Z., Ittu, M., and Kaur, N. 2017a. Characterization of Pyrenophora tritici-repentis (tan spot of wheat) races in Baltic States and Romania. Plant Pathol. J. 33:133-139.

Abdullah, S., Sehgal, S. K., Glover, K. D., and Ali, S. 2017b. Reaction of global collection of rye (Secale cereale L.) to tan spot and Pyrenophora tritici-repentis races in South Dakota. Plant Pathol. J. 33:229-237.
Aboukhaddour, R., Cloutier, S., Lamari, L., and Strelkov, S. E. 2011. Simple sequence repeats and diversity of globally distributed populations of Pyrenophora tritici-repentis. Can. J. Plant Pathol. 33:389-399.

Aboukhaddour, R., Turkington, T. K., and Strelkov, S. E. 2013. Race structure of Pyrenophora tritici-repentis (tan spot of wheat) in Alberta, Canada. Can. J. Plant Pathol. 35:256-268.

Alam, K. B., and Gustafson, J. P. 1988. Tan-spot resistance screening of Aegilops species. Plant Breed. 100:112-118.

Ali, S., and Francl, L. J. 2002. A new race of Pyrenophora tritici-repentis from Brazil. Plant Dis. 86:1050.

Ali, S., and Francl, L. J. 2003. Population race structure of Pyrenophora triticirepentis prevalent on wheat and noncereal grasses in the Great Plains. Plant Dis. 87:418-422.

Ali, S., Gurung, S., and Adhikari, T. B. 2010. Identification and characterization of novel isolates of Pyrenophora tritici-repentis from Arkansas. Plant Dis. 94:229-235.

Amaike, S., Ozga, J. A., Basu, U., and Strelkov, S. E. 2008. Quantification of ToxB gene expression and formation of appressoria by isolates of Pyrenophora tritici repentis differing in pathogenicity. Plant Pathol. 57: 623-633.

Ameen, G., Kariyawasam, G., Shi, G., Friesen, T. L., Faris, J. D., Ali, S., Rasmussen, J. B., and Liu, Z. 2017. Molecular manipulation of the mating-type system and development of a new approach for characterizing pathogen virulence in Pyrenophora tritici-repentis. Fungal Genet. Biol. 109:16-25.

Andrie, R. M., and Ciuffetti, L. M. 2011. Pyrenophora bromi, causal agent of brownspot of bromegrass, expresses a gene encoding a protein with homology and similar activity to Ptr ToxB, a host-selective toxin of wheat. Mol. Plant-Microbe Interact. 24:359-367.

Andrie, R. M., Schoch, C. L., Hedges, R., Spatafora, J. W., and Ciuffetti, L. M. 2008. Homologs of ToxB, a host-selective toxin gene from Pyrenophora tritici-repentis, are present in the genome of sister-species Pyrenophora bromi and other members of the Ascomycota. Fungal Genet. Biol. 45: 363-377.

Aung, T. S. G. 2001. Molecular polymorphism and virulence in Pyrenophora tritici-repentis. MS thesis. The University of Manitoba, Canada.

Balance, G., Lamari, L., Kowatsch, R., and Bernier, C. 1996. Cloning, expression and occurrence of the gene encoding the Ptr necrosis toxin from Pyrenophora tritici-repentis. Mol. Plant Pathol. Online 1996/1209ballance.

Barrus, M. F. 1942. Yellow-spot disease of wheat in New York State. Plant Dis. Rep. 26:246-247.

Benslimane, H. 2018. Virulence phenotyping and molecular characterization of a new virulence type of Pyrenophora tritici-repentis the causal agent of tan spot. Plant Pathol. J. 34:139-142.

Benslimane, H., Lamari, L., Benbelkacem, A., Sayoud, R., and Bouzand, Z. 2011. Distribution of races of Pyrenophora tritici-repentis in Algeria and identification of a new virulence type. Phytopathol. Mediterr. 50:203-211.

Bertagnolli, V. V., Ferreira, J. R., Liu, Z., Rosa, A. C., and Deuner, C. C. 2019. Phenotypical and genotypical characterization of Pyrenophora triticirepentis races in Brazil. Eur. J. Plant Pathol. 154:995-1007.

Chu, C. G., Chao, S., Friesen, T. L., Faris, J. D., Zhong, S., and Xu, S. S. 2010. Identification of novel tan spot resistance QTLs using an SSR-based linkage map of tetraploid wheat. Mol. Breed. 25:327-338.

Chu, C. G., Friesen, T. L., Xu, S. S., and Faris, J. D. 2008. Identification of novel tan spot resistance loci beyond the known host-selective toxin insensitivity genes in wheat. Theor. Appl. Genet. 117:873-881.

Ciuffetti, L. M., Manning, V. A., Pandelova, I., Betts, M. F., and Martinez, J. P. 2010. Host-selective toxins, Ptr ToxA and Ptr ToxB, as necrotrophic effectors in the Pyrenophora tritici-repentis-wheat interaction. New Phytol. 187:911-919.

Ciuffetti, L. M., Tuori, R. P., and Gaventa, J. M. 1997. A single gene encodes a selective toxin causal to the development of tan spot of wheat. Plant Cell 9: 135-144.

Effertz, R. J., Meinhardt, S. W., Anderson, J. A., Jordahl, J. G., and Francl, L. J. 2002. Identification of a chlorosis-inducing toxin from Pyrenophora tritici-repentis and the chromosomal location of an insensitivity locus in wheat. Phytopathology 92:527-533.

Elias, E. M., and Miller, J. D. 1998. Registration of 'Ben' durum wheat. Crop Sci. 38:895.

Faris, J. D., Abeysekara, N. S., McClean, P. E., Xu, S. S., and Friesen, T. L. 2012. Tan spot susceptibility governed by the $T s n 1$ locus and racenonspecific resistance quantitative trait loci in a population derived from the wheat lines Salamouni and Katepwa. Mol. Breed. 30:1669-1678.

Faris, J. D., Liu, Z., and Xu, S. S. 2013. Genetics of tan spot resistance in wheat. Theor. Appl. Genet. 29:1-21.

Faris, J. D., Overlander, M. E., Kariyawasam, G. K., Carter, A., Xu, S. S., and Liu, Z. 2020. Identification of a major dominant gene for race-nonspecific tan spot resistance in wild emmer wheat. Theor. Appl. Genet. 133:829-841.

Fernandez, M. R., DePauw, R. M., Clarke, J. M., and Lefkovitch, L. P. 1996. Red smudge in durum wheat reduces seedling vigor. Can. J. Plant Sci. 76:321-324. 
Friesen, T. L., Ali, S., Kianian, S., Francl, L. J., and Rasmussen, J. B. 2003. Role of host sensitivity to Ptr ToxA in development of tan spot of wheat. Phytopathology 93:397-401.

Friesen, T. L., Ali, S., Klein, K. K., and Rasmussen, J. B. 2005. Population genetic analysis of a global collection of Pyrenophora tritici-repentis, causal agent of tan spot of wheat. Phytopathology 95:1144-1150.

Friesen, T. L., Holmes, D. J., Bowden, R., and Faris, J. D. 2018. ToxA is present in the U.S. Bipolaris sorokiniana population and is a significant virulence factor on wheat harboring Tsn1. Plant Dis. 102:2446-2452.

Friesen, T. L., Stukenbrock, E. H., Liu, Z., Meinhardt, S., Ling, H., Faris, J. D., Rasmussen, J. B., Solomon, P. S., McDonald, B. A., and Oliver, R. P. 2006. Emergence of a new disease as a result of interspecific virulence gene transfer. Nat. Genet. 38:953-956.

Friesen, T. L., Xu, S. S., and Harris, M. O. 2008. Stem rust, tan spot, Stagonospora nodorum blotch, and hessian fly resistance in Langdon durumAegilops tauschii synthetic hexaploid wheat lines. Crop Sci. 48:1062-1070.

Friskop, A., and Liu, Z. 2016. Fungal leaf spot diseases of wheat: Tan spot, Stagonospora nodorum blotch and Septoria tritici blotch. North Dakota State University Extension Service.

Galagedara, N., Liu, Y., Fiedler, J., Shi, G., Chao, S., Xu, S. S., Faris, J. D., and Liu, Z. 2020. Genome-wide association mapping of tan spot resistance in a worldwide collection of durum wheat. Theor. Appl. Genet. 13:2227-2237.

Gamba, F. M., and Lamari, L. 1998. Mendelian inheritance of resistance to tan spot (Pyrenophora tritici-repentis) in selected genotypes of durum wheat (Triticum turgidum). Can. J. Plant Pathol. 20:408-414.

Gamba, F. M., Strelkov, S. E., and Lamari, L. 2012. Virulence of Pyrenophora tritici-repentis in the southern cone region of South America. Can. J. Plant Pathol. 34:545-550.

Guo, J., Shi, G., and Liu, Z. 2018. Characterizing virulence of the Pyrenophora tritici-repentis isolates lacking both ToxA and ToxB genes. Pathogens 7:74

Hosford, R. M., Jr. 1982. Tan spot-developing knowledge 1902-1981, virulent races and wheat differentials, methodology, rating systems, other leaf diseases, and literature. Page 1-24 in: Tan Spot of Wheat and Related Diseases Workshop. Agricultural Experimental Station, North Dakota State University, Fargo, North Dakota.

Hu, W., He, X., Dreisigacker, S., Sansaloni, C. P., Juliana, P., and Singh, P. K. 2019. A wheat chromosome 5AL region confers seedling resistance to both tan spot and Septoria nodorum blotch in two mapping populations. Crop J. 7:809-818

Joehanes, R., and Nelson, J. C. 2008. QGene 4.0, an extensible Java QTL analysis platform. Bioinformatics 24:2788-2789.

Kamel, S., Cherif, M., Hafez, M., Despins, T., and Aboukhaddour, R. 2019. Pyrenophora tritici-repentis in Tunisia: Race structure and effector genes. Front. Plant Sci. 10:1562.

Kariyawasam, G. K., Carter, A. H., Rasmussen, J. B., Faris, J., Xu, S. S., Mergoum, M., and Liu, Z. 2016. Genetic relationships between racenonspecific and race-specific interactions in the wheat-Pyrenophora triticirepentis pathosystem. Theor. Appl. Genet. 129:897-908.

Lamari, L., and Bernier, C. C. 1989a. Evaluation of wheat lines and cultivars to tan spot Pyrenophora tritici-repentis based on lesion type. Can. J. Plant Pathol. 11:49-56.

Lamari, L., and Bernier, C. C. 1989b. Virulence of isolates of Pyrenophora tritici-repentis on 11 wheat cultivars and cytology of the differential host reactions. Can. J. Plant Pathol. 11:284-290.

Lamari, L., and Bernier, C. C. 1991. Genetics of tan necrosis and extensive chlorosis in tan spot of wheat caused by Pyrenophora tritici-repentis. Phytopathology 81:1092-1095.

Lamari, L., Bernier, C. C., and Smith, R. B. 1991. Wheat genotypes that develop both tan necrosis and extensive chlorosis in response to isolates of Pyrenophora tritici-repentis. Plant Dis. 75:121-122.

Lamari, L., Gilbert, J., and Tekauz, A. 1998. Race differentiation in Pyrenophora tritici-repentis and survey of physiologic variation in western Canada. Can. J. Plant Pathol. 20:396-400.

Lamari, L., Sayoud, R., Boulif, M., and Bernier, C. C. 1995. Identification of a new race in Pyrenophora tritici-repentis: implications for the current pathotype classification system. Can. J. Plant Pathol. 17:312-318.

Lamari, L., and Strelkov, S. E. 2010. Minireview/Minisynthèse: The wheat/ Pyrenophora tritici-repentis interaction: Progress towards an understanding of tan spot disease. Can. J. Plant Pathol. 32:4-10.

Lamari, L., Strelkov, S. E., Yahyaoui, A., Amedov, M., Saidov, M., Djunusova, M., and Koichibayev, M. 2005. Virulence of Pyrenophora tritici-repentis in the countries of the Silk Road. Can. J. Plant Pathol. 27:383-388.

Lamari, L., Strelkov, S. E., Yahyaoui, A., Orabi, J., and Smith, R. B. 2003. The identification of two new races of Pyrenophora tritici-repentis from the host center of diversity confirms a one-to-one relationship in tan spot of wheat. Phytopathology 93:391-396.

Lepoint, P., Renard, M. E., Legrève, A., Duveiller, E., and Maraite, H. 2010. Genetic diversity of the mating type and toxin production genes in Pyrenophora tritici-repentis. Phytopathology 100:474-483.
Levene, H. 1960. Robust tests for equality of variances. Pages 278-292 in: Contributions to Probability and Statistics: Essays in Honor of Harold Hotelling. I. Olkin, S. H. Ghurye, W. Hoeffding, W. G. Madow, and H. B. Maan, eds. Stanford University Press, Stanford, Palo Alto, CA.

Liu, Y., Salsman, E., Wang, R., Galagedara, N., Zhang, Q., Fiedler, J. D., Liu, Z., Xu, S. S., Faris, J. D., and Li, X. 2020b. Meta-QTL analysis of tan spot resistance in wheat. Theor. Appl. Genet. 133:2363-2375.

Liu, Y., Zhang, Q., Salsman, E., Fiedler, J. D., Hegstad, J. B., Liu, Z., Faris, J. D., Xu, S. S., and Li, X. 2020a. QTL mapping of resistance to tan spot induced by race 2 of Pyrenophora tritici-repentis in tetraploid wheat. Theor. Appl. Genet. 133:433-442.

Liu, Z., El-Basyoni, I., Kariyawasam, G., Zhang, G., Fritz, A., Hansen, J. M., Marais, F., Friskop, A. J., Chao, S., Akhunov, E., and Baenziger, P. S. 2015. Evaluation and association mapping of resistance to tan spot and Stagonospora nodorum blotch in adapted winter wheat germplasm. Plant Dis. 99: 1333-1341.

Liu, Z., Friesen, T. L., Ling, H., Meinhardt, S. W., Oliver, R. P., Rasmussen, J. B., and Faris, J. D. 2006. The Tsn1-ToxA interaction in the wheatStagonospora nodorum pathosystem parallels that of the wheat-tan spot system. Genome 49:1265-1273.

Liu, Z., Zurn, J. D., Kariyawasam, G., Faris, J. D., Shi, G., Hansen, J., Rasmussen, J. B., and Acevedo, M. 2017. Inverse gene-for-gene interactions contribute additively to tan spot susceptibility in wheat. Theor. Appl. Genet. 130:1267-1276.

Manning, V. A., Pandelova, I., Dhillon, B., Wilhelm, L. J., Goodwin, S. B., Berlin, A. M., Figueroa, M., Freitag, M., Hane, J. K., Henrissat, B., Holman, W. H., Kodira, C. D., Martin, J., Oliver, R. P., Robbertse, B., Schackwitz, W., Schwartz, D. C., Spatafora, J. W., Turgeon, B. G., Yandava, C., Young, S., Zhou, S., Zeng, Q., Grigoriev, I. V., Ma, L. J., and Ciuffetti, L. M. 2013. Comparative genomics of a plant-pathogenic fungus, Pyrenophora tritici-repentis, reveals transduplication and the impact of repeat elements on pathogenicity and population divergence. G3 (Bethesda) 3:41-63.

Maraite, H. 1997. Evolution of the nomenclature used for Helminthosporium spp. causing leaf blight of wheat. Pages 6-9 in: Helminthosporium Blights of Wheat: Spot Blotch and Tan Spot. H. Duveiller, H. J. Dubin, J. Reeves, and A. McNab, eds. CIMMYT, Mexico D. F.

Martinez, J. P., Oesch, N. W., and Ciuffetti, L. M. 2004. Characterization of the multiple-copy host-selective toxin gene, ToxB, in pathogenic and nonpathogenic isolates of Pyrenophora tritici-repentis. Mol. Plant-Microbe Interact. 17:467-474.

Martinez, J. P., Ottum, S. A., Ali, S., Francl, L. J., and Ciuffetti, L. M. 2001. Characterization of the ToxB gene from Pyrenophora tritici-repentis. Mol. Plant-Microbe Interact. 14:675-677.

McDonald, M. C., Ahren, D., Simpfendorfer, S., Milgate, A., and Solomon, P. S. 2018. The discovery of the virulence gene ToxA in the wheat and barley pathogen Bipolaris sorokiniana. Mol. Plant Pathol. 19: 432-439.

Moolhuijzen, P., See, P. T., Hane, J. K., Shi, G., Liu, Z., Oliver, R. P., and Moffat, C. S. 2018. Comparative genomics of the wheat fungal pathogen Pyrenophora tritici-repentis reveals chromosomal variations and genome plasticity. BMC Genomics 19:279.

Murray, G. M., and Brennan, J. P. 2009. Estimating disease losses to the Australian wheat industry. Australas. Plant Pathol. 38:558-570.

Navathe, S., Yadav, P. S., Chand, R., Mishra, V. K., Vasistha, N. K., Meher, P. K., Joshi, A. K., and Gupta, P. K. 2020. ToxA-Tsn1 interaction for spot blotch susceptibility in Indian wheat: An example of inverse gene-for-gene relationship. Plant Dis. 104:71-81.

Rees, R. G., and Platz, G. J. 1992. Tan spot and its control—some Australian experiences. Pages 1-9 in: Advances in Tan Spot Research. L. J. Francl, J. M. Krupinsky, and M. P. McMullen, eds. North Dakota Agric. Exp. Station, Fargo.

Rees, R. G., Platz, G. J., and Mayer, R. J. 1982. Yield losses in wheat from yellow spot: Comparison of estimates derived from single tillers and plots. Aust. J. Agric. Res. 33:899-908.

Sarova, J., Hanzalova, A., and Bartos, P. 2005. Races of Pyrenophora triticirepentis in the Czech Republic. Acta Agrobot. 58:73-78.

Shjerve, R. A., Faris, J. D., Brueggeman, R. S., Yan, C., Zhu, Y., Koladia, V., and Friesen, T. L. 2014. Evaluation of a Pyrenophora teres f. teres mapping population reveals multiple independent interactions with a region of barley chromosome 6H. Fungal Genet. Biol. 70:104-112.

Singh, P. K., Mergoum, M., and Hughes, G. R. 2007. Variation in virulence to wheat in Pyrenophora tritici-repentis population from Saskatchewan, Canada, from 2000 to 2002. Can. J. Plant Pathol. 29:166-171.

Snedecor, G. W., and Cochran, W. G. 1989. Statistical Methods, 8th Ed. Iowa State University Press, Ames, IA.

Strelkov, S. E., Kowatsch, R. F., Balance, G. M., and Lamari, L. 2006. Characterization of the ToxB gene from North African and Canadian isolates of Pyrenophora tritici-repentis. Physiol. Mol. Plant Pathol. 67:164-170. 
Strelkov, S. E., and Lamari, L. 2003. Host parasite interactions in tan spot (Pyrenophora tritici-repentis) of wheat. Can. J. Plant Pathol. 25: 339-349.

Virdi, S. K., Liu, Z., Overlander, M. E., Zhang, Z., Xu, S. S., Friesen, T. L., and Faris, J. D. 2016. New insights into the roles of host genenecrotrophic effector interactions in governing susceptibility of durum wheat to tan spot and Septoria nodorum blotch. G3: Genes, Genomes, Genetics 6:4139-4150.
White, T. J., Bruns, T., Lee, S. J. W. T., and Taylor, J. 1990. Amplification and direct sequencing of fungal ribosomal RNA genes for phylogenetics. Pages 315-322 in: PCR Protocols: A Guide to Methods and Applications. Academic Press.

Zhang, Q., Axtman, J. E., Faris, J. D., Chao, S., Zhang, Z., Friesen, T. L., Zhong, S., Cai, X., Elias, M. E., and Xu, S. S. 2014. Identification and molecular mapping of quantitative trait loci for Fusarium head blight resistance in emmer and durum wheat using a single nucleotide polymorphism-based linkage map. Mol. Breed. 34:1677-1687. 